\title{
Investigating The Definitions of Metabolic Syndrome Among High School Students in Taipei and The Optimal Cutoff Points of Relevant Risk Factors
}

\author{
Shao Chia Chiu Lin \\ Taipei City Hospital Heping Branch https://orcid.org/0000-0001-6599-2205 \\ Mei-Ju Chen ( $\sim$ DXD41@tpech.gov.tw)
}

\section{Research}

Keywords: metabolic syndrome, adolescents, body mass index, cardiometabolic risk factor, waist circumference

Posted Date: June 10th, 2020

DOI: https://doi.org/10.21203/rs.3.rs-34076/v1

License: @ (1) This work is licensed under a Creative Commons Attribution 4.0 International License. Read Full License 


\section{Abstract}

Background:

The effects of different definitions for metabolic syndrome (MetS) on its prevalence were examined, and the differences in the discriminatory power, as well as the optimal cutoff points of relevant risk factors, were analyzed in this study.

Methods:

45,756 health checkup data sets from 2011 to 2014 of high school students aged between 15 to 17 years were sourced in Taipei city. The database included the students' gender, age, height, weight, waist circumference (WC), systolic and diastolic blood pressure, as well as biochemical markers such as triglycerides (TG), high-density lipoprotein cholesterol, and fasting glucose (FG) levels. The ROC curve statistical approach was used to analyze the discriminatory power and optimal cutoff points of the relevant MetS risk factors.

Results:

The prevalence of MetS among adolescents in Taipei was 2.3\% and 1.2\%, according to the criteria of the modified National Cholesterol Education Program Adult Treatment Panel III (NCEP ATP III) and the International Diabetes Federation (IDF) respectively. The prevalence increased to $4.3 \%$ when this study's criteria were used. Among the components of MetS analyzed, WC and TG had stronger discriminatory powers, while FG had the weakest. The optimal cutoff point for WC was approximately the 90 th percentile, while that for the TG was similar to the criteria of the modified NCEP ATP III. About $44.6 \%$ of adolescents had at least one MetS component. Body mass index also had good discriminatory power.

Conclusions:

The prevalence of MetS differs depending on the diagnostic criteria used. Redefining the cutoff points for the components of MetS in adolescents in different regions, as well as further screening and intervention, are crucial to prevent cardiovascular disease and type 2 diabetes mellitus in the future.

\section{Introduction}

Childhood and adolescent overweight and obesity are major concerns in developed countries [1]. According to the 2010-2011 Nutrition and Health Survey in Taiwan (NAHSIT), the prevalence among Taiwanese adolescents aged between 11 and 18 years of overweight and obesity was $12.4 \%$ and $16.8 \%$, respectively [2]. With the number of overweight and obese adolescents on the rise, the prevalence of metabolic syndrome (MetS) has also escalated, and has a positive correlation with obesity [3]. From 1988 to 1994 , the prevalence of MetS among American adolescents aged 12 to 19 years was $28.7 \%$ in overweight subjects (BMI $\geq 95$ th percentile), which was significantly higher than the prevalence of $6.8 \%$ and $0.1 \%$ in subjects with a BMI in the 85th to 95th percentile and low-risk subjects (BMI < 85th percentile), respectively [3]. Research has shown that cardiometabolic risk factors identified in childhood and adolescence are associated with subclinical atherosclerosis in adulthood [4]. The presence of MetS during childhood exacerbates the risk of having adulthood MetS, cardiovascular disease (CVD), and type 2 diabetes mellitus (T2DM) [5, 6]. Therefore, screening of MetS and obesity during childhood and adolescence, as well as further interventions (especially changes in diet and increase physical activity), are important factors to improve the future health of the adult population [7].

MetS comprises of the risk factors for CVD and T2DM [8]. It represents the association between obesity, insulin resistance, hypertension, dyslipidemia, T2DM, and CVD [9]. In 1988, Reaven first proposed the notion of insulin resistance (IR), and named the cluster of risk factors for CVD and diabetes as "Syndrome X" [10]. In 1998, the World Health Organization (WHO) formally named the syndrome as MetS and defined its criteria [11]. Afterwards, various definitions were proposed, such as that of the European Group for the Study of Insulin Resistance (EGIR) in 1999 [12]; the National Cholesterol Education Program Adult Treatment Panel III(NCEP ATP III) in 2001 [13]; the International Diabetes Federation (IDF) [14] and the American Heart Association/National Heart, Lung, and Blood Institute (AHA/NHLBI) [15] in 2005. Early studies suggested IR as the primary cause of MetS [16], but subsequent studies deduced that the interaction between obesity, IR, and inflammation plays a crucial role in the development of MetS [17]. Moreover, MetS is influenced by other metabolic and pathological factors such as inflammatory factors, adipocytokines, cortisol, oxidative stress, vascular factors, inheritance, and lifestyle factors [9]..

Loading [MathJax]/jax/output/CommonHTML/fonts/TeX/fontdata.js 
The unified criteria for diagnosing MetS in adults have been determined [8] and successfully applied in clinical practice and research [9]. However, due to the growing concern about MetS in children and adolescents, many studies have attempted to define MetS in these groups [9]. At present, as there are no unified diagnostic criteria, the difficulty in defining the condition may be associated with physiological changes during growth, racial differences, lack of CVD cases, and lack of clinical trials[18]. Consequently, the discrepancies in the prevalence of MetS in children and adolescents is remarkably large as there is no unified diagnostic criteria. Many studies have modified the NCEP ATP III's definition of MetS in adults [19], while recent studies commonly adopt the modified NCEP ATP III criteria and the 2007 IDF criteria [20]. Based on the modified NCEP ATP III criteria, the prevalence of MetS in American, Korean, and Chinese adolescents was 8.6\% (2001- 2006) [21], 5.7\% (2010- 2012) [22], and 3.7\% (2008) [23], respectively. It must be noted, however, that cutoff points for abnormal MetS factors had different sources in these three studies. Based on the IDF criteria, the prevalence of MetS in Taiwanese, Korean, and American adolescents was 3\% (2010-2011) [24], 2.1\% (2010-2012) [22], and $4.24 \%(2011-2016)$ [25], respectively.

This study aimed to elucidate the influence that different definitions of MetS used to categorize first year senior high school students in Taipei City had on the prevalence of MetS reported, as well as to analyze the differences in the discriminatory power and the optimal cutoff points for relevant risk factors. The results can serve as a reference for the future definition of MetS in adolescents and to enable early intervention measures.

\section{Methods}

\section{Study population and data collection}

This study was approved by the institutional review board of the Taipei City Hospital (TCHIRB-10811003-E). The personal health data of high school students aged between 15 to 17 years who underwent health checkups at a district hospital from 2011 to 2014 was sourced from the hospital's database. There were 50,280 sets of data. After omitting those with missing information, a total of 45,756 sets of data were included in this study.

The database of this study included the subjects' gender, age, height, weight, systolic blood pressure (SBP), diastolic blood pressure (DBP), and waist circumference (WC), as well as biochemical markers such as triglycerides (TG), high-density lipoprotein cholesterol (HDL-C), and fasting glucose (FG) levels.

Height was measured using a standard stadiometer and measured height (in $\mathrm{cm}$ ) was rounded to the first decimal place. Weight was measured with a standard weighing scale and measured weight (in $\mathrm{kg}$ ) was rounded to the first decimal place. To measure blood pressure (BP), a subject was told to sit in a relaxed manner, and their BP was measured by placing their left arm into a tunnel-type electronic sphygmomanometer. The recorded BP was taken as the mean of two measurements. To measure WC, a measuring tape was kept parallel to the ground and was wrapped around a subject's waist, starting from a point midway between the upper iliac crest margin and the lower rib margin. The recorded WC was taken after the subject had breathed out. A subject's body mass index (BMI) was taken as their weight in kilograms divided by the square of their height in meters.

\section{Definition of MetS}

In this study, three definitions for the prevalence of MetS were compared: the modified NCEP ATP III proposed by Ford et al. [26]; the 2007 IDF [20]; and the new criteria based on the cutoff points of this study's receiver operating characteristic (ROC) curves. All of these diagnostic criteria include the five components of WC, TG, HDL-C, BP, and FG. The modified NCEP ATP III served as a baseline for the criteria of this study, in which the optimal cutoff point of each MetS component with an area under the ROC curve (AUC) greater than 0.8 were taken as new components (modified WC, TG, and HDL-C). The components of BP and FG remained unchanged (see Table 1).

\section{Statistics}

The statistical approaches used to analyze the discriminatory power and optimal cutoff points of relevant MetS risk factors in this study included descriptive statistics, chi-squared tests, independent sample t-tests, and ROC curves. 
Table 1

Comparison of definitions for MetS criteria

\begin{tabular}{|c|c|c|c|c|}
\hline & Modified NCEP ATP III & \multicolumn{2}{|l|}{ IDF } & \multirow{3}{*}{$\begin{array}{l}\text { This studya } \\
\text { Present with three or more } \\
\text { of the five components }\end{array}$} \\
\hline $\begin{array}{l}\text { Diagnostic } \\
\text { criteria }\end{array}$ & $\begin{array}{l}\text { CPresent with three or more } \\
\text { of the five components }\end{array}$ & \multicolumn{2}{|c|}{$\begin{array}{l}\text { Present with central obesity and two or more of the four } \\
\text { components }\end{array}$} & \\
\hline & & $<16$ years old & $\geqq 16$ years old & \\
\hline WC & $\begin{array}{l}\geq 90 \text { th percentile (adjusted } \\
\text { for age and gender) }\end{array}$ & $\begin{array}{l}\text { Z90th percentile } \\
\text { (adjusted for age and } \\
\text { gender) }\end{array}$ & $\geqq 90 \mathrm{~cm}$ for males; $\geqq 80 \mathrm{~cm}$ for females & $\begin{array}{l}\geqq 86.8 \mathrm{~cm} \text { for males } \\
\geqq 76.25 \mathrm{~cm} \text { for females }\end{array}$ \\
\hline TG & $\geqq 110 \mathrm{mg} / \mathrm{dL}$ & $\geqq 150 \mathrm{mg} / \mathrm{dL}$ & $\begin{array}{l}\geqq 150 \mathrm{mg} / \mathrm{dL} \text { or currently under drug } \\
\text { treatment }\end{array}$ & $\begin{array}{l}\geqq 108 \mathrm{mg} / \mathrm{dL} \text { for males } \\
\geqq 104.05 \mathrm{mg} / \mathrm{dL} \text { for } \\
\text { females }\end{array}$ \\
\hline HDL-C & $<40 \mathrm{mg} / \mathrm{dL}$ & $<40 \mathrm{mg} / \mathrm{dL}$ & $\begin{array}{l}<40 \mathrm{mg} / \mathrm{dL} \text { for males and }<50 \mathrm{mg} / \mathrm{dL} \text { for } \\
\text { females, or is currently under drug } \\
\text { treatment }\end{array}$ & $\begin{array}{l}<46.5 \mathrm{mg} / \mathrm{dL} \text { for males } \\
<54.5 \mathrm{mg} / \mathrm{dL} \text { for females }\end{array}$ \\
\hline BP & $\begin{array}{l}\gtrless 90 \text { th percentile (adjusted } \\
\text { for age, gender, and height) }\end{array}$ & $\geqq 130 / 85 \mathrm{mmHg}$ & $\begin{array}{l}\geqq 130 / 85 \mathrm{mmHg} \text { or currently under drug } \\
\text { treatment }\end{array}$ & $\begin{array}{l}\gtrless 90 \text { th percentile (adjusted } \\
\text { for age, gender, and height) }\end{array}$ \\
\hline \begin{tabular}{|l} 
FG \\
BP:
\end{tabular} & $\begin{array}{l}\geqq 100 \mathrm{mg} / \mathrm{dL} \\
\text { pressure: FG: fasting alucos }\end{array}$ & $\begin{array}{l}\geqq 100 \mathrm{mg} / \mathrm{dL} \text { or diagn } \\
\text { se; HDL-C: high-density } \\
\text { ational Cholesterol Educ } \\
\text { T2DM: type } 2 \text { diabetes }\end{array}$ & $\begin{array}{l}\text { osed with T2DM } \\
\text { ipoprotein cholesterol; IDF: International Di } \\
\text { :ation Program, Adult Treatment Panel III; RC } \\
\text { mellitus; WC: waist circumference. }\end{array}$ & $\begin{array}{l}\geq 100 \mathrm{mg} / \mathrm{dL} \\
\text { betes Federation; MetS: } \\
\text { C curve: receiver operating }\end{array}$ \\
\hline & & & IC & \\
\hline
\end{tabular}

\section{Results}

The results of this study are shown in Table 2. The male subjects had a mean age of $15.18 \pm 0.41$ years; a mean height of $170.63 \pm$ $6.14 \mathrm{~cm}$; a mean weight of $63.74 \pm 13.54 \mathrm{~kg}$; a mean BMI of $21.81 \pm 4.33 \mathrm{~kg} / \mathrm{m}^{2}$; a mean WC of $72.29 \pm 10.66 \mathrm{~cm}$; a mean SBP of $117.23 \pm 15.18 \mathrm{mmHg}$; a mean DBP of $61.75 \pm 11.23 \mathrm{mmHg}$; a mean TG level of $72.87 \pm 36.20 \mathrm{mg} / \mathrm{dL}$; a mean HDL-C level of $56.66 \pm$ $11.37 \mathrm{mg} / \mathrm{dL}$; and a mean FG level of $84.76 \pm 9.55 \mathrm{mg} / \mathrm{dL}$.

The female subjects had a mean age of $15.19 \pm 0.41$ years; a mean height of $159.28 \pm 5.53 \mathrm{~cm}$; a mean weight of $52.60 \pm 9.35 \mathrm{~kg}$; a mean BMl of $20.67 \pm 3.43 \mathrm{~kg} / \mathrm{m}^{2}$; a mean WC of $67.02 \pm 7.80 \mathrm{~cm}$; a mean SBP of $106.13 \pm 13.33 \mathrm{mmHg}$; a mean DBP of $62.82 \pm$ $9.81 \mathrm{mmHg}$; a mean TG level of $68.89 \pm 27.16 \mathrm{mg} / \mathrm{dL}$; a mean HDL-C level of $63.38 \pm 12.74 \mathrm{mg} / \mathrm{dL}$; and a mean FG level of $83.73 \pm$ $9.09 \mathrm{mg} / \mathrm{dL}$.

In general, the male subjects had a significantly $(p<0.001)$ higher height, weight, BMI, WC, SBP, DBP, TG, HDL-C, and FG than their female counterparts. 
Table 2

Comparison of relevant data and biochemical markers in male and female subjects

\begin{tabular}{|c|c|c|c|}
\hline \multirow[t]{3}{*}{ Variable } & Males & Females & \multirow[t]{3}{*}{$\mathrm{Pa}$} \\
\hline & $(n=27,168)$ & $(n=18,588)$ & \\
\hline & Mean \pm SD & Mean \pm SD & \\
\hline Age (years) & $15.18 \pm 0.41$ & $15.19 \pm 0.41$ & ** \\
\hline Height (cm) & $170.63 \pm 6.14$ & $159.28 \pm 5.53$ & *** \\
\hline Weight (kg) & $63.74 \pm 13.54$ & $52.60 \pm 9.35$ & $* \star *$ \\
\hline $\mathrm{BMI}\left(\mathrm{kg} / \mathrm{m}^{2}\right)$ & $21.81 \pm 4.33$ & $20.67 \pm 3.43$ & *** \\
\hline WC (cm) & $72.29 \pm 10.66$ & $67.02 \pm 7.80$ & *** \\
\hline SBP $(\mathrm{mmHg})$ & $117.23 \pm 15.18$ & $106.13 \pm 13.33$ & $* * *$ \\
\hline $\mathrm{DBP}(\mathrm{mmHg})$ & $61.75 \pm 11.23$ & $62.82 \pm 9.81$ & *** \\
\hline $\mathrm{TG}(\mathrm{mg} / \mathrm{dL})$ & $72.87 \pm 36.20$ & $68.89 \pm 27.16$ & *** \\
\hline HDL-C (mg/dL) & $56.66 \pm 11.37$ & $63.38 \pm 12.74$ & *** \\
\hline $\mathrm{FG}(\mathrm{mg} / \mathrm{dL})$ & $84.76 \pm 9.55$ & $83.73 \pm 9.09$ & *** \\
\hline \multicolumn{4}{|c|}{$\begin{array}{l}\text { BMI: body mass index; DBP: diastolic blood pressure; FG: fasting glucose; HDL-C: high-density lipoprotein cholesterol; SBP: } \\
\text { systolic blood pressure; TG: triglycerides; WC: waist circumference. }\end{array}$} \\
\hline
\end{tabular}

The relevant MetS risk factors of the first year senior high school students have different discriminatory powers toward the diagnosis of MetS (Fig. 1 and Table 3). Table 3 lists the discriminatory power of each MetS component in descending order according to their AUC values. The top four components with the highest AUC values in the male subjects were WC (AUC $=0.942$, sensitivity $=0.89$, specificity = 0.917); BMI (AUC=0.926, sensitivity =0.9, specificity =0.85); TG (AUC=0.924, sensitivity =0.87, specificity $=0.902)$; and HDL-C (AUC $=0.825$, sensitivity $=0.674$, specificity $=0.832$. . The top four components with the highest AUC values in the female subjects were WC $(A U C=0.937$, sensitivity $=0.918$, specificity $=0.904)$; TG $(A U C=0.931$, sensitivity $=0.883$, specificity $=0.922)$; BMI (AUC $=0.915$, sensitivity $=0.817$, specificity $=0.902)$; and $\mathrm{HDL}-\mathrm{C}(A \cup C=0.827$, sensitivity $=0.763$, specificity $=0.752)$. Generally speaking, the subjects' WC, BMI, and TG had the highest discriminatory power, sensitivity, and specificity.

For the male subjects, the cutoff points for the main components of MetS were WC, TG, HDL-C, SBP, DBP, and FG was $86.8 \mathrm{~cm}$, $108 \mathrm{mg} / \mathrm{dL}, 46.5 \mathrm{mg} / \mathrm{dL}, 128 \mathrm{mmHg}, 67.5 \mathrm{mmHg}$, and $91.5 \mathrm{mg} / \mathrm{dL}$, respectively. For the female subjects, their WC, TG, HDL-C, SBP, DBP, and FG was $76.25 \mathrm{~cm}, 104.05 \mathrm{mg} / \mathrm{dL}, 54.5 \mathrm{mg} / \mathrm{dL}, 117.5 \mathrm{mmHg}, 72.5 \mathrm{mmHg}$, and $93.5 \mathrm{mg} / \mathrm{dL}$, respectively. 
Table 3

Optimal cutoff points of the ROC curves of relevant MetS components

\begin{tabular}{|c|c|c|c|c|c|}
\hline & AUC & Youden index & Optimal cutoff point & Sensitivity (\%) & Specificity (\%) \\
\hline \multicolumn{6}{|l|}{ Males } \\
\hline WC & 0.942 & 0.81 & 86.8 & 0.89 & 0.917 \\
\hline TG & 0.924 & 0.772 & 108 & 0.87 & 0.902 \\
\hline BMI & 0.926 & 0.75 & 25.6 & 0.9 & 0.85 \\
\hline HDL-C & 0.825 & 0.507 & 46.5 & 0.674 & 0.832 \\
\hline SBP & 0.767 & 0.413 & 128 & 0.65 & 0.763 \\
\hline DBP & 0.709 & 0.338 & 67.5 & 0.602 & 0.736 \\
\hline FG & 0.629 & 0.192 & 91.5 & 0.361 & 0.831 \\
\hline \multicolumn{6}{|c|}{ Females } \\
\hline WC & 0.937 & 0.823 & 76.25 & 0.918 & 0.904 \\
\hline TG & 0.931 & 0.805 & 104.05 & 0.883 & 0.922 \\
\hline BMI & 0.915 & 0.719 & 24.65 & 0.817 & 0.902 \\
\hline HDL-C & 0.827 & 0.515 & 54.5 & 0.763 & 0.752 \\
\hline SBP & 0.791 & 0.483 & 117.5 & 0.665 & 0.818 \\
\hline DBP & 0.786 & 0.478 & 72.5 & 0.615 & 0.863 \\
\hline FG & 0.64 & 0.266 & 93.5 & 0.346 & 0.919 \\
\hline \multicolumn{6}{|c|}{$\begin{array}{l}\text { BMI: body mass index; DBP: diastolic blood pressure; FG: fasting glucose; HDL-C: high-density lipoprotein cholesterol; MetS: } \\
\text { metabolic syndrome; SBP: systolic blood pressure; TG: triglycerides; WC: waist circumference. }\end{array}$} \\
\hline \multicolumn{6}{|c|}{$\begin{array}{l}\text { The prevalence of MetS among first year senior high school students in Taipei was } 2.3 \%, 1.2 \% \text {, and } 4.3 \% \text { according to the criteria } \\
\text { of the modified NCEP ATP III, the IDF, and this study, respectively (Table 4). Using the modified ATP III criteria, the prevalence of } \\
\text { each MetS component was, in decreasing order, } 18.6 \% \text { for BP; } 10.6 \% \text { for WC; } 9.7 \% \text { for TG; } 4.2 \% \text { for HDL-C; and } 2.9 \% \text { for FG; } 34.4 \% \\
\text { of the students had at least one component. Using the IDF criteria, the prevalence of each MetS component was, in decreasing } \\
\text { order, } 15.7 \% \text { for BP; } 10.1 \% \text { for WC; } 5.1 \% \text { for HDL-C; } 2.9 \% \text { for FG; and } 2.9 \% \text { for TG; } 28.3 \% \text { of adolescents had at least one } \\
\text { component. Applying the criteria developed in this study, the prevalence of each MetS component was, in decreasing order, } 21.2 \% \\
\text { for HDL-C; } 18.6 \% \text { for BP; } 10.8 \% \text { for TG; } 10.7 \% \text { for WC; and } 2.9 \% \text { for FG; } 44.6 \% \text { of adolescents had at least one component. For all } \\
\text { three of the diagnostic criteria (modified NCEP ATP III, the IDF, and this study), except WC, the differences in the prevalence of } \\
\text { MetS and the MetS components (TG, HDL-C, BP, and FG) between male and female subjects were all statistically significant (p< } \\
0.001 \text { ). }\end{array}$} \\
\hline
\end{tabular}


Table 4

Comparison of the prevalence of MetS and its components

\begin{tabular}{|c|c|c|c|c|c|c|c|c|c|c|c|c|}
\hline & \multicolumn{3}{|l|}{ Total } & \multicolumn{3}{|c|}{ Modified NCEP ATP III } & \multicolumn{3}{|l|}{ IDF } & \multicolumn{3}{|c|}{ This study } \\
\hline & $\begin{array}{l}\text { Modified } \\
\text { NCEP } \\
\text { ATP III }\end{array}$ & IDF & $\begin{array}{l}\text { This } \\
\text { study }\end{array}$ & Males & Females & $\mathrm{Pa}^{\mathrm{a}}$ & Males & Females & $P^{a}$ & Males & Females & $\mathbf{P}^{a}$ \\
\hline MetS (\%) & 2.3 & 1.2 & 4.3 & 3 & 1.4 & $\begin{array}{l}< \\
0.001\end{array}$ & 1.8 & 0.5 & $\begin{array}{l}< \\
0.001\end{array}$ & 4.6 & 3.8 & $\begin{array}{l}<.001 \\
0.0\end{array}$ \\
\hline \multicolumn{13}{|c|}{ MetS components } \\
\hline $\begin{array}{l}\text { Central } \\
\text { obesity } \\
\text { (elevated } \\
\text { WC) (\%) }\end{array}$ & 10.6 & 10.1 & 10.7 & 10.8 & 10.4 & 0.222 & 10.3 & 9.8 & 0.089 & 10.8 & 10.7 & 0.833 \\
\hline $\begin{array}{l}\text { High TG } \\
(\%)\end{array}$ & 9.7 & 2.9 & 10.8 & 11.4 & 7.3 & $\dot{0} 001$ & 3.7 & 1.6 & $\dot{0} 001$ & 12.1 & 8.9 & $\begin{array}{l}<.001 \\
0.001\end{array}$ \\
\hline $\begin{array}{l}\text { Low } \\
\text { HDL-C } \\
(\%)\end{array}$ & 4.2 & 5.1 & 21.2 & 5.8 & 2 & $\dot{0} 001$ & 5.8 & 4.2 & $\dot{0} 001$ & 18.3 & 25.5 & $\begin{array}{l}<.001 \\
0.001\end{array}$ \\
\hline $\begin{array}{l}\text { Elevated } \\
\text { BP (\%) }\end{array}$ & 18.6 & 15.7 & 18.6 & 19.3 & 17.7 & $<001$ & 22.3 & 6.1 & $<001$ & 19.3 & 17.7 & $\begin{array}{l}<.001 \\
0.00\end{array}$ \\
\hline $\begin{array}{l}\text { Elevated } \\
\text { FG (\%) }\end{array}$ & 2.9 & 2.9 & 2.9 & 3.4 & 2.3 & $\begin{array}{l}<.001 \\
0.00\end{array}$ & 3.4 & 2.3 & $\begin{array}{l}< \\
0.001\end{array}$ & 3.4 & 2.3 & $\hat{0.001}$ \\
\hline \multicolumn{13}{|c|}{ Numbers of MetS components } \\
\hline 1 & 25.4 & 22.1 & 30.2 & 26 & 24.4 & \multirow{5}{*}{ <. 001} & 26.2 & 16.5 & \multirow{5}{*}{$\dot{0} 001$} & 29 & 32.1 & \multirow{5}{*}{$\begin{array}{l}<.001 \\
0.00\end{array}$} \\
\hline 2 & 6.6 & 5 & 10.1 & 7.5 & 5.4 & & 6.6 & 3 & & 9.9 & 10.3 & \\
\hline 3 & 1.9 & 1 & 3.3 & 2.5 & 1.1 & & 1.6 & 0.4 & & 3.5 & 2.9 & \\
\hline 4 & 0.4 & 0.2 & 0.9 & 0.5 & 0.3 & & 0.3 & 0.1 & & 1 & 0.8 & \\
\hline 5 & 0 & 0 & 0.1 & 0 & 0 & & 0 & 0 & & 0.1 & 0.1 & \\
\hline \multicolumn{13}{|c|}{$\begin{array}{l}\text { BMl: body mass index; BP: blood pressure; FG: fasting glucose; HDL-C: high-density lipoprotein cholesterol; IDF: International } \\
\text { Diabetes Federation; MetS: metabolic syndrome; NCEP ATP III: National Cholesterol Education Program, Adult Treatment Panel III; } \\
\text { TG: triglycerides; WC: waist circumference. }\end{array}$} \\
\hline
\end{tabular}

\section{Discussion}

MetS in adolescents and the prevalence of its components

At present, there are no unified criteria for diagnosing MetS in adolescents, which makes it difficult to compare between studies in the literature. The prevalence of MetS differs across studies, which could be associated with differences in diagnostic criteria, age (especially IR in adolescents), gender, regions, and races [7]. In this study, the prevalence of MetS as measured using the modified NCEP ATP III and IDF criteria was $2.3 \%$ and $1.2 \%$, respectively. These values were lower than those summarized in literature [21-25]. The prevalence of MetS measured using this study's criteria was $4.3 \%$ and there were significant differences observed between males and females. In particular, MetS was more prevalent in males than females, which is in line with an American study [7].

Differences in the percentage of abnormal measures of MetS components are a result of different diagnostic criteria. According to this study's criteria, $10.7 \%$ of high school students had a slightly large WC, $10.8 \%$ had high TG, and $21.2 \%$ had low HDL-C. The study population had a higher percentage of individuals with abnormal measures for these three components than for the other two components (elevated BP and elevated FG). 
The criteria developed in this study identified a significantly higher percentage of subjects with low HDL-C (21.2\%), compared to that seen using the modified NCEP ATP III (4.2\%) and the IDF (5.1\%). A possible explanation could be that a unified criterion ( $<40 \mathrm{mg} / \mathrm{dL})$ was used in the modified NCEP ATP III (in which subjects were 12 to 19 years old) and the IDF (in which subjects were below 16 years old). Moreover, gender differences were not adjusted for in the cutoff values, which resulted in a low prevalence among females. This has also been observed in another study [24].

Differences were observed between the results from the modified NCEP ATP III and IDF in the percentage of individuals with abnormal measures for TG $(9.7 \%$ vs. $2.9 \%)$ and BP $(18.6 \%$ vs. $15.7 \%)$. This is because the modified NCEP ATP III criteria define elevated BP as $\geqq 90$ th percentile after adjusting for age, gender, and height, while high TG are defined as $\geqq 110 \mathrm{mg} / \mathrm{dL}$ after adjusting for age [3], whereas the IDF criteria define elevated BP in adults as $\geqq 130 / 85 \mathrm{mmHg}$ and high TG as $\geqq 150 \mathrm{mg} / \mathrm{dL}$.

Compared with the modified NCEP ATP III criteria adjusted by Ford et al.[26], the percentage of subjects identified as having a large WC in this study (10.6\%) was similar to that in a Korean population (9.7\%) [22], but lower than that in an American population (19.1\%) [21]; the percentage of subjects with elevated BP in this study(18.6\%) was also similar to that in a Korean population (20.4\%), but higher than that in an American population (6.9\%). These differences could due to differences in the populations, which indicates the importance of establishing a large database on the WC and BP of people in different regions. The percentage of subjects with high TG in this study $(9.7 \%)$ was lower than that in studies conducted in Korea $(21.2 \%)$ and the USA $(25.6 \%)$; the percentage of subjects with low HDL-C in this study(4.2\%) was lower than that in Korea (11.6\%) and the USA (19.3\%); and the percentage of subjects with elevated FG was $2.9 \%$, which is significantly lower than that in the USA (14\%) and Korea (11.4\%) [21, 22]. The components of MetS in adolescents must be adjusted for regional differences. This highlights the importance of the results of this study.

Moreover, according to the criteria of the modified NCEP ATP III, the IDF, and this study, about $34.4 \%, 28.3 \%$, and $44.6 \%$ of adolescents, respectively, had at least one MetS component. The fewer of these components that are present during childhood, the lower the cardiovascular risk in the future [27]. Some researchers [28] have emphasized that the effects of metabolic risk factor clustering are more important than diagnosing MetS in children. Based on these arguments, it is not only crucial to detect MetS in adolescents, but those present with MetS components despite not yet reaching the diagnostic criteria should receive attention as well, to provide prompt intervention and prevention $[7,28]$.

The predictive power of MetS components

According to the results of this study, WC has the highest predictive power, sensitivity, and specificity, regardless of gender. This is in agreement with other studies which have suggested that WC is a good indicator for predicting MetS during adolescence $[25,29,30]$ and adulthood [31]. A study on American adolescents between 12 and 19 years of age revealed that abdominal obesity was closely associated with MetS and other MetS components [25]. Another study on 15-year old Greek teenagers showed that a WC at the 75th percentile or higher is closely related to the phenotypes of MetS [29]; while a study on Chinese adolescents between 11 and 16 years old indicated that WC has the best predictive power toward MetS [30].

To determine the optimal cutoff point for WC, Cook et al. (2003) [3] took into account the differences between adolescents and adults, and defined abdominal obesity as at the 90th percentile or higher, in 2004, de Ferranti et al.[32] adopted a value at the 75th percentile or higher as their standard; afterward, in 2007, the IDF study (in which subjects were below 16 years of age) [20] and numerous studies $[21,22,26]$ adopted a WC at the 90 th percentile or higher as their standards. A Chinese study on children and adolescents between 7 and 18 years of age found that a WC at the 75th percentile and the 90th percentile was the optimal cutoff point for predicting the risk of cardiovascular risk [33]. The optimal cutoff point for WC specified in this study was $86.8 \mathrm{~cm}$ for males and $76.25 \mathrm{~cm}$ for females, which was around the 90 th percentile and similar to that of the previous studies.

In this study, TG level also had adequate predictive power, with an optimal cutoff point of $108 \mathrm{mg} / \mathrm{dL}$ for males and $104.05 \mathrm{mg} / \mathrm{dL}$ for females, similar to that of the modified NCEP ATP III criteria $(<110 \mathrm{mg} / \mathrm{dL})$. Even though the sensitivity and specificity of HDL-C were slightly inadequate, gender differences were also observed for HDL-C in this study. These results highlight that definitions should be specific for gender. According to the criteria of the modified NCEP ATP III and the IDF, male subjects in this study had a higher prevalence of high TG, low HDL-C, elevated BP, and high FG than their female counterparts. After adjusting the criteria of this study, the prevalence of low HDL-C significantly increased for both genders, in which females (25.5\%) had a higher prevalence than males (18.3\%).

Loading [MathJax]/jax/output/CommonHTML/fonts/TeX/fontdata.js 
SBP, DBP, and FG had weaker predictive powers. In particular, FG had the weakest predictive power, which was also observed in other studies with adolescents [30] and adult [31] subjects. Furthermore, according to the IDF criteria, the prevalence of elevated BP was significantly higher in males (22.3\%) than females (6.1\%). This could be caused by the use of unified criteria for adults ( $\geqq$ $130 / 85 \mathrm{mmHg}$ ) that neglects gender differences in BP.

In this study, the cutoff points for MetS components were redefined based on the results of first year high school students in Taipei. This indicates that it is necessary to take into account regional differences when determining definition criteria.

The predictive power of BMI

Based on the results of this study, BMI also had good predictive power on MetS in adolescents, after that of WC and TG. The optimal cutoff point for males was between the 80 th to 85 th percentile $\left(25.6 \mathrm{~kg} / \mathrm{m}^{2}\right)$ for males and approximately the 90th percentile $\left(24.65 \mathrm{~kg} / \mathrm{m}^{2}\right)$ for females.

The WC and BMI of adolescents are good predictive indicators of cardiovascular risk factors [34]. A longitudinal study highlighted the close association between BMI and many other cardiometabolic risk factors, while changes in WC mainly have a stronger correlation with FG [35]. A study on children and adolescents between 8 and 19 years of age [36] revealed that a high BMI has strong predictive power for cardiometabolic risk factors. In addition, the sensitivity of BMI is higher among obese adolescents while its specificity is higher among overweight adolescents [37].

The definitions of overweight and obesity are currently based on a person's BMI, and their criteria differ for adolescents [37-39]. In 2007, the WHO defined overweight as having a BMI between the 85th and 95th percentiles, while obesity is defined as having a BMI greater than the 95th percentile [37]; in 2012, the International Obesity Task Force (IOTF) deduced the cutoff points for BMI in adolescents and adults after mathematical adjustments based on the definition of overweight and obesity in adults I [38, 39]. One study [40] used the three aforementioned criteria (WHO; Conde and Monteiro; IOTF) to analyze Brazilian adolescents between 12 and 20 years old; it revealed that the IOTF criteria had the best predictive power for MetS (AUC $=0.75-0.89$ ), with a sensitivity ranging from $59.4-84.2 \%$ and a specificity ranging from $88.2 \%$ to $93.6 \%$. In contrast, according to this study's adjusted definition of MetS, BMI had a better predictive power (AUC $=0.915-0.926)$ and sensitivity $(0.817-0.9)$ for the high school students. The differences between these results and those of the aforementioned studies could be due to the differences in the diagnostic criteria, age, region, and race in adolescents [7].

Limitations

The cross-sectional research design of this study hindered observations of the causal relationships in the data. Moreover, the subjects were adolescents from an urban region of northern Taiwan, which limited the extrapolation of results to adolescents in rural locations as well as those with special circumstances. However, the results of this study are still valuable and can serve as a reference for defining MetS in Taipei adolescents. This study analyzed the differences in the discriminatory power of relevant risk factors as well as their optimal cutoff points, which could provide markers for early interventions in the future. Subsequent research could include the potential confounders of MetS, such as the influence of puberty and temporary IR during adolescence [7]; as well as taking into account more biochemical markers, and participating in cross-regional and cross-cultural cohort studies. A combination of these approaches would make the understanding of MetS in Taiwanese adolescents more comprehensive.

\section{Conclusion}

The prevalence of MetS in adolescents differs when measured using different criteria. In comparison to the results with the criteria of the modified NCEP ATP III and the IDF, the criteria defined in this study found that the prevalence of MetS among adolescents in Taipei City was higher (4.3\%). Of the MetS components, WC and TG had the strongest discriminatory power, sensitivity, and specificity, while FG had the weakest discriminatory power. The optimal cutoff point for WC was approximately at the 90th percentile; while the optimal cutoff point for TG was similar to the criteria of the modified NCEP ATP III. Moreover, about $44.6 \%$ of adolescents had at least one MetS component. The early detection of relevant risk factors during adolescence is a crucial issue as it provides vital information for prevention and intervention, to reducing the risk of CVD and T2DM in the future. For accurate detection, it is necessary to redefine the cutoff points for MetS components specific to adolescents in different regions, to establish suitable criteria for adolescents in Taiwan as a whole.

\section{Abbreviations}

Loading [MathJax]/jax/output/CommonHTML/fonts/TeX/fontdata.js 
AHAVNHLBI: American Heart Association/National Heart, Lung, and Blood Institute; AUC: area under the ROC curve; CVD: cardiovascular disease; BP: blood pressure; DBP: diastolic blood pressure; EGIR: European Group for the Study of Insulin Resistance; FG: fasting glucose; HDL-C: high-density lipoprotein cholesterol; IDF: International Diabetes Federation; IR: insulin resistance; MetS: metabolic syndrome; NAHSIT: Nutrition and Health Survey in Taiwan; NCEP ATP III: National Cholesterol Education Program, Adult Treatment Panel III; ROC curve: receiver operating characteristic curve; SBP: systolic blood pressure; TG: triglycerides; T2DM: type 2 diabetes mellitus; WC: waist circumference; WHO: World Health Organization.

\section{Declarations}

Ethics approval and consent to participate

The study was conducted with the approval of the Taipei City Institutional Review Board (TCHIRB-10811003-E).

Consent for publication

Not applicable.

Availability of data and materials

All data generated or analysed during this study are included in this published article.

Competing interests

All the authors declared no competing interests.

Funding

This study is supported by the research fund of Heping Fuyou Branch of Taipei City Hospital (No TPCH-10-42).

Authors' contributions

SCCL and MJC participated in study design, data analysis and interpretation. SCCL wrote the manuscript. MJC reviewed the manuscript. All authors read and approved the final manuscript.

\section{Acknowledgements}

We would like to thank research program support from Heping Fuyou Branch of Taipei City Hospital.

Author details

${ }^{1}$ Department of Family Medicine, Taipei City Hospital, Heping Fuyou Branch, Taipei, Taiwan

${ }^{2}$ National Taipei University of Nursing and Health Sciences, Taipei, Taiwan

\section{References}

1. Wang Y, Lobstein T. Worldwide trends in childhood overweight and obesity. Int J Pediatr Obes. 2006;1(1):11-25.

2. Chen CM, Lou MF, Gau BS. Parental Body Mass Index Is Associated With Adolescent Obesity in Taiwan. Res Nurs Heal. 2016;39(6):399-405.

3. Cook S, Weitzman M, Auinger P, Nguyen M, Dietz WH. Prevalence of a Metabolic Syndrome Phenotype in Adolescents: findings from the third National Health and Nutrition Examination Survey, 1988-1994. Arch Pediatr Adolesc Med. 2003;157:821-7.

4. Juonala M, Järvisalo MJ, Mäki-Torkko N, Kähönen M, Viikari JSA, Raitakari OT. Risk factors identified in childhood and decreased carotid artery elasticity in adulthood: The cardiovascular risk in young finns study. Circulation. 2005;112(10):1486-93.

5. Morrison JA, Friedman LA, Gray-McGuire C. Metabolic syndrome in childhood predicts adult cardiovascular disease 25 years later: The Princeton lipid research clinics follow-up study. Pediatrics. 2007;120(2):340-5. 
6. Morrison JA, Friedman LA, Wang P, Glueck CJ. Metabolic Syndrome in Childhood Predicts Adult Metabolic Syndrome and Type 2 Diabetes Mellitus 25 to 30 Years Later. J Pediatr. 2008;152(2):201-6.

7. Deboer MD. Assessing and managing the metabolic syndrome in children and adolescents. Nutrients. 2019;11(8):1788.

8. Alberti KGMM, Eckel RH, Grundy SM, Zimmet PZ, Cleeman JI, Donato KA, et al. Harmonizing the metabolic syndrome: A joint interim statement of the international diabetes federation task force on epidemiology and prevention; National heart, lung, and blood institute; American heart association; World heart federation; International. Circulation. 2009;120(16):1640-5.

9. Steinberger J, Daniels SR, Eckel RH, Hayman L, Lustig RH, McCrindle B, et al. Progress and challenges in metabolic syndrome in children and adolescents. A Scientific Statement from the American Heart Association Atherosclerosis, Hypertension, and Obesity in the Young Committee of the Council on Cardiovascular Disease in the Young. Circulation. 2009;119(4):628-47.

10. Reaven GM. Role of insulin resistance in human disease. Diabetes. 1988;37(12):1595-607.

11. Alberti KGMM, Zimmet PZ. Definition, diagnosis and classification of diabetes mellitus and its complications. Part 1: Diagnosis and classification of diabetes mellitus. Provisional report of a WHO consultation. Diabet Med. 1998;15(7):539-53.

12. Balkau B, Charles MA. Comment on the provisional report from the WHO consultation. Diabet Med. 1999;16(5):442-3.

13. Expert Panel on Detection E and T of HBC in A. Executive Summary of the Third Report (NCEP) -Adult Treatment Panel III. J Am Med Assoc. 2001;285(19):2486-97.

14. Alberti KGMM, Zimmet P, Shaw J. The metabolic syndrome - A new worldwide definition. Lancet. 2005;366(9491):1059-62.

15. Grundy SM, Cleeman JI, Daniels SR, Donato KA, Eckel RH, Franklin BA, et al. Diagnosis and management of the metabolic syndrome: An American Heart Association/National Heart, Lung, and Blood Institute scientific statement. Circulation. 2005;112(17):2735-52.

16. 10.1016/j.mcna.2011.06.002

Reaven GM. Insulin Resistance: The Link Between Obesity and Cardiovascular Disease. Med Clin North Am [Internet]. 2011;95(5):875-92. Available from: http://dx.doi.org/10.1016/j.mcna.2011.06.002.

17. Wittcopp C, Conroy R. Metabolic syndrome in children and adolescents. Pediatr Rev. 2016;37(5):193-202.

18. Pérez EA, Olivares VM, Martínez-Espinosa RM, Vila MDM, García-Galbis MR. New insights about how to make an intervention in children and adolescents with metabolic syndrome: Diet, exercise vs. changes in body composition. A systematic review of RCT. Nutrients. 2018;10(7):878.

19. Ford ES, Li C. Defining the Metabolic Syndrome in Children and Adolescents: Will the Real Definition Please Stand Up? J Pediatr. 2008;152(2):160-4.

20. Zimmet P, Alberti KGM, Kaufman F, Tajima N, Silink M, Arslanian S, et al. The metabolic syndrome in children and adolescents an IDF consensus report. Pediatr Diabetes. 2007;8:299-306.

21. Johnson WD, Kroon JJM, Greenway FL, Bouchard C, Ryan D, Katzmarzyk PT. Prevalence of Risk Factors for Metabolic Syndrome in Adolescents. Arch Pediatr Adolesc Med. 2009;163(4):371-7.

22. Kim S, So WY. Prevalence of metabolic syndrome among Korean adolescents according to the national cholesterol education program, adult treatment panel III and international diabetes federation. Nutrients. 2016;8(10):588.

23. Li Y, Yang X, Zhai F, Kok FJ, Zhao W, Piao J, et al. Prevalence of the metabolic syndrome in Chinese adolescents. Br J Nutr. 2008;99(3):565-70.

24. Lin WT, Lee CY, Tsai S, Huang HL, Wu PW, Chin YT, et al. Clustering of metabolic risk components and associated lifestyle factors: A nationwide adolescent study in Taiwan. Nutrients. 2019;11(3).

25. 10.1016/j.annepidem.2018.11.009

Gaston SA, Tulve NS, Ferguson TF. Abdominal obesity, metabolic dysfunction, and metabolic syndrome in U.S. adolescents: National Health and Nutrition Examination Survey 2011-2016. Ann Epidemiol [Internet]. 2019;30:30-6. Available from: https://doi.org/10.1016/j.annepidem.2018.11.009.

26. Ford ES, Li C, Cook S, Choi HK. Serum concentrations of uric acid and the metabolic syndrome among US children and adolescents. Circulation. 2007;115(19):2526-32.

27. Chen W, Srinivasan SR, Li S, Xu J, Berenson GS. Metabolic Syndrome Variables at Low Levels in Childhood Are Beneficially Associated With Adulthood Cardiovascular Risk. Diabetes Care. 2005;28(April 2004):138-43. 
28. Magge SN, Goodman E, Armstrong SC, Daniels S, Corkins M, De Ferranti S, et al. The metabolic syndrome in children and adolescents: Shifting the focus to cardiometabolic risk factor clustering. Pediatrics. 2017;140(2):e20171603.

29. Bitsori $M$, Linardakis $M$, Tabakaki $M$, Kafatos $A$. Waist circumference as a screening tool for the identification of adolescents with the metabolic syndrome phenotype. Int J Pediatr Obes. 2009;4(4):325-31.

30. Wang ZN, Li P, Jiang RH, Li L, Li X, Li L, et al. The association between serum uric acid and metabolic syndrome among adolescents in northeast China. Int J Clin Exp Med. 2015;8(11):21122-9.

31. 10.1016/j.metabol.2008.11.014

Chedid R, Gannagé-Yared MH, Khalifé S, Halaby G, Zoghbi F. Impact of different metabolic syndrome classifications on the metabolic syndrome prevalence in a young Middle Eastern population. Metabolism [Internet]. 2009;58(6):746-52. Available from: http://dx.doi.org/10.1016/j.metabol.2008.11.014.

32. De Ferranti SD, Gauvreau K, Ludwig DS, Neufeld EJ, Newburger JW, Rifai N. Prevalence of the metabolic syndrome in American adolescents: Findings from the Third National Health and Nutrition Examination Survey. Circulation. 2004;110(16):2494-7.

33. Ma GS, Ji CYE, Ma J, Mi J, Sung RYT, Xiong F, et al. Waist circumference reference values for screening cardiovascular risk factors in chinese children and adolescents. Biomed Environ Sci. 2010;23(1):21-31.

34. Messiah SE, Arheart KL, Lipshultz SE, Miller TL. Body Mass Index, Waist Circumference, and Cardiovascular Risk Factors in Adolescents. J Pediatr. 2008;153(6):6-12.

35. Jago R, Mendoza JA, Chen T, Baranowski T. Longitudinal associations between BMI, waist circumference, and cardiometabolic risk in US youth: Monitoring implications. Obesity. 2013;21(3):271-9.

36. 10.1371/journal.pone.0149351

Sardinha LB, Santos DA, Silva AM, Grøntved A, Andersen LB, Ekelund U. A comparison between BMI, waist circumference, and waist-to-height ratio for identifying cardio-metabolic risk in children and adolescents. PLoS One [Internet]. 2016;11(2):e0149351. Available from: http://dx.doi.org/10.1371/journal.pone.0149351.

37. Onis M de, Onyango AW, Borghi E, Siyam A, Nishida C, Siekmann J. Development of a WHO growth reference for school-aged children and adolescents. Bull World Health Organ. 2007;85(9):660-7.

38. Cole TJ, Lobstein T. Extended international (IOTF) body mass index cut-offs for thinness, overweight and obesity. Pediatr Obes. 2012;7(4):284-94.

39. Conde WL, Monteiro CA. Body mass index cutoff points for evaluation of nutritional status in Brazilian children and adolescents. J Pediatr (Rio J). 2006;82(4):266-72.

40. Oliveira RG de, Guedes DP. Performance of different diagnostic criteria of overweight and obesity as predictors of metabolic syndrome in adolescents. J Pediatr (Rio J). 2017;93(5):525-31.

\section{Figures}
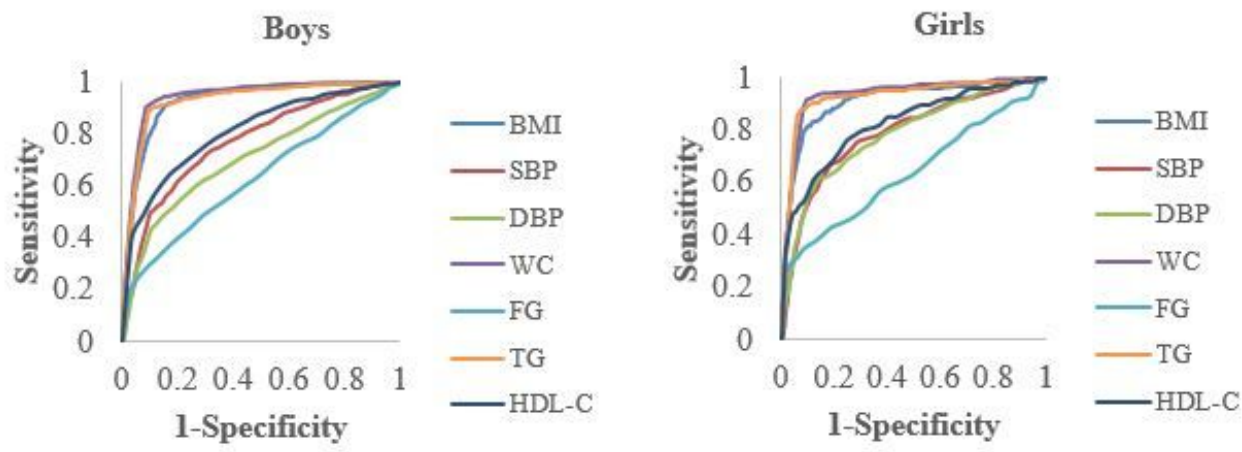

Figure 1

ROC curves of relevant MetS risk factors for boys (left) and girls (right).

Loading [MathJax]/jax/output/CommonHTML/fonts/TeX/fontdata.js 